\title{
The $\mathrm{ED}_{50}$ and $\mathrm{ED}_{95}$ of oxytocin infusion rate for maintaining uterine tone during elective caesarean delivery: a dose-finding study
}

Xiao Wei Qian ${ }^{1}$, Dan M. Drzymalski ${ }^{2}$, Chang Cheng Lv ${ }^{1}$ Fei He Guo ${ }^{1}$, Lu Yang Wang ${ }^{1}$ and Xin Zhong Chen ${ }^{1 *}$ (D)

\begin{abstract}
Background: The $90 \%$ effective dose $\left(\mathrm{ED}_{90}\right)$ of oxytocin infusion has been previously estimated to be $16.2 \mathrm{IU} \mathrm{h}^{-1}$. However, bolus administration of oxytocin prior to the infusion may decrease the infusion dose required. The aim of this study was to estimate the $\mathrm{ED}_{95}$ for oxytocin infusion after a bolus at elective caesarean delivery (CD) in nonlaboring parturients.

Methods: We performed a randomized, triple blinded study in 150 healthy termparturients scheduled for elective CD under epidural anaesthesia. After delivery of the infant and i.v. administration of $1 \mathrm{IU}$ oxytocin as a bolus, Participants were randomized to receive oxytocin infusion at a rate of $0,1,2,3,5$, or $8 \mathrm{IU} \mathrm{h}^{-1}$, to be given for a total of $1 \mathrm{~h}$. Uterine tone assessed by the blinded obstetrician as either adequate or inadequate. Secondary outcomes included estimated blood loss (EBL), requirement for supplemental uterotonic agents, and development of side effects.

Results: The 95\% effective dose (ED95) of oxytocin infusion was estimated to be $7.72 \mathrm{IU} \mathrm{h}^{-1}$ (95\% confidence interval 5.80-12.67 $\left.\mathrm{U} \mathrm{U} \mathrm{h}^{-1}\right)$. With increasing oxytocin infusion rate, the proportion of parturients who needed rescue oxytocin bolus or secondary uterotonic agents decreased. No significant among-group differences in the EBL and oxytocin-related side effects were observed.

Conclusions: In parturients who receive a $1 \mathrm{IU}$ bolus of oxytocin during elective cesarean delivery, an infusion rate of oxytocin at $7.72 \mathrm{IU} \mathrm{h}^{-1}$ will produce adequate uterine tone in $95 \%$ of parturients. These results suggest that the total dose of oxytocin administered in the postpartum period can be decreased when administered as an infusion after oxytocin bolus.
\end{abstract}

Keywords: Caesarean section, Oxytocin, Postpartum haemorrhage prevention

\section{Background}

Although oxytocin has been administered for postpartum haemorrhage prophylaxis for several decades [1], there still remains considerable variability in the approach to its administration during caesarean delivery (CD). As an example, a slow i.v. bolus dose of up to $5 \mathrm{IU}$ has been advocated by several authors [2, 3], but Carvalho et al. estimated the minimum effective dose (ED)

\footnotetext{
* Correspondence: chenxinz@zju.edu.cn

${ }^{1}$ Department of Anesthesia, Women's Hospital, Zhejiang University School of Medicine, Xueshi Road 1, Hangzhou 310006, China

Full list of author information is available at the end of the article
}

of oxytocin bolus to result in adequate tone in $90 \%$ of parturients $\left(\mathrm{ED}_{90}\right)$ during elective $\mathrm{CD}$ in nonlaboring parturients to be $0.35 \mathrm{IU}$ [4]. These results suggest that doses lower than those commonly used would not only be effective, but would also decrease the risks of side effects [4-8].

When administered as an infusion, Lavoie et al. estimated the $\mathrm{ED}_{90}$ of oxytocin during elective $\mathrm{CD}$ in nonlaboring women to be $16.2 \mathrm{IU} \mathrm{h}^{-1}$ [5]. While this approach is effective, it exposes patients to significant amounts of oxytocin in the postpartum period. Part of the reason that the $\mathrm{ED}_{90}$ is so high with this approach is

(c) The Author(s). 2019 Open Access This article is distributed under the terms of the Creative Commons Attribution 4.0 International License (http://creativecommons.org/licenses/by/4.0/), which permits unrestricted use, distribution, and reproduction in any medium, provided you give appropriate credit to the original author(s) and the source, provide a link to the Creative Commons license, and indicate if changes were made. The Creative Commons Public Domain Dedication waiver (http://creativecommons.org/publicdomain/zero/1.0/) applies to the data made available in this article, unless otherwise stated. 
because the infusion needs to be administered for some duration of time prior to achieving therapeutic plasma levels.

By administering an oxytocin bolus prior to initiation of infusion, therapeutic plasma concentrations are rapidly achieved and are simply maintained by the infusion [5]. Therefore, the aim of this study was to estimate the $\mathrm{ED}_{95}$ (the minimum effective dose (ED) of oxytocin bolus to result in adequate tone in $95 \%$ of parturients) for oxytocin infusion after a bolus at elective $C D$ in nonlaboring parturients. Our hypothesis was that the $\mathrm{ED}_{95}$ of the infusion would be lower than in previous studies that did not administer a bolus prior to the infusion.

\section{Methods}

The Ethical Committee of the Women's Hospital, Zhejiang University School of Medicine (Hangzhou, China) approved this study on April 5, 2018 (No. 20180010). This study was registered on the Chinese Clinical Trial Register (ChiCTR1800015532).

The study was performed at the Women's Hospital, Zhejiang University School of Medicine from April 9 to July 31, 2018. After providing written informed consent, 150 healthy term parturients scheduled for elective CD were enrolled in this prospective, randomized, tripleblinded, placebo-controlled, dose-finding study. The present study adhered to CONSORT guideline.

Inclusion criteria were American Society of Anaesthesiologists Physical Status II, age 18-40 years old, body mass index $<40 \mathrm{~kg} / \mathrm{m}^{2}$, singleton pregnancy, $\geq 37$ weeks' gestation age, elective $\mathrm{CD}$ planned with a Pfannenstiel incision, and planning epidural anaesthesia. Parturients were only recruited if the individual performing the $C D$ was 1 of 5 experienced obstetricians who agreed to have their patients participate in this study. Exclusion criteria included maternal refusal, emergency $\mathrm{CD}$, active labor, ruptured membranes, pregnancy-induced hypertension, placental abnormalities (including placenta previa), multiple gestation, uterine fibroids, history of prior peripartum hemorrhage, coagulation disorders, oxytocin allergy, contraindication to epidural anaesthesia, and the need for pharmacological anxiolysis.

Prior to initiation of this study, sealed, opaque envelopes were prepared using the Microsoft Excel RAND function to determine study subject allocation. Participants were randomized to oxytocin infusion at a rate of $0,1,2,3,5$, or $8 \mathrm{IU} \mathrm{h}^{-1}$, to be given for a total of $1 \mathrm{~h}$. On the day of surgery, an anaesthetist not involved in the study prepared an oxytocin infusion according to the randomization assignment. After filling a syringe with the total number of units of oxytocin that were to be administered during the hour-long infusion (e.g. if the patient were randomized to receive $8 \mathrm{IU} \mathrm{h}^{-1}$, a total of $8 \mathrm{IU}$ were drawn into the syringe), the syringe was filled with normal saline to make a total volume of $50 \mathrm{ml}$. This syringe was then given to the anaesthetist of record with instructions to administer the infusion at $50 \mathrm{ml}$ over $1 \mathrm{~h}$. By having all study subjects receive the same infusion rate $\left(50 \mathrm{ml} \mathrm{h}^{-1}\right)$ but with a different total dose of oxytocin, the study subject, obstetrician, and anaesthetist responsible for the care of the patient were all blinded to the actual dose of oxytocin.

Upon entry into the operation room, an 18-gauge i.v. catheter was placed in the study subject's lower forearm and $500 \mathrm{ml}$ lactated Ringer's solution was administered. With the parturient in the left lateral decubitus position, an epidural catheter was placed at the $\mathrm{L}_{1-2}$ interspace by an anaesthetist not involved in the study. Lidocaine $2 \%$ with epinephrine 1:200,000 was administered in $5 \mathrm{ml}$ increments to a total of $15-20 \mathrm{ml}$ until a T6 sensory level to pinprick was obtained.

Upon initiation of epidural anaesthesia, non-invasive blood pressure (NIBP) and maternal heart rate (HR) were measured at 3-min intervals. An i.v. bolus of ephedrine $5 \mathrm{mg}$ was administrated when hypotension was accompanied by bradycardia $\left(\mathrm{HR}<50\right.$ beats $\left.\mathrm{min}^{-1}\right)$, and an i.v. bolus of phenylephrine $100 \mu \mathrm{g}$ was administrated when hypotension occurred without bradycardia. Hypotension was defined as a decrease in systolic blood pressure greater than $20 \%$ from baseline, which had been previously estimated upon admission by the averaging of three consecutive measurements.

Surgery commenced with onset of adequate surgical anaesthesia. After clamping of the umbilical cord and delivery of the infant, all parturients were given an i.v. bolus of oxytocin $1 \mathrm{IU}$ over $15 \mathrm{~s}$ as previously recommended [6], after which the oxytocin infusion previously prepared according to the randomization scheme was initiated at $50 \mathrm{ml} \mathrm{h}^{-1}$.

After initiation of the oxytocin infusion, uterine tone (UT) was assessed by the obstetrician as adequate or inadequate every $3 \mathrm{~min}$ until the peritoneum was closed based on previously described methods [5-7]. If UT was assessed as inadequate, an i.v. bolus of oxytocin $1 \mathrm{U}$ was administered. If UT was still judged to be inadequate after two such oxytocin boluses, then secondary uterotonic agents (i.m. carboprost tromethamine $0.25 \mathrm{mg}$ or i.v. carbetocin $0.1 \mathrm{mg}$ ) were administered upon the obstetrician's request. The oxytocin infusion was continued until discharge from the post anaesthetic care unit (PACU). If another syringe was needed in PACU, the same dose of oxytocin as the original was prepared.

The primary study outcome was adequacy of UT during the CD. Secondary outcomes included estimated blood loss (EBL), hemoglobin $(\mathrm{Hb})$ and haematocrit (HCT) levels (at time of PACU discharge and on postoperative day 1), proportion of participants requiring administration of supplemental oxytocin boluses or alternative uterotonic 
agents, and side effects (hypotension, bradycardia, tachycardia [defined as $\mathrm{HR} \geq 120$ beats $\mathrm{min}^{-1}$ ], nausea, vomiting, flushing, chest pain, or dyspnea). Postpartum

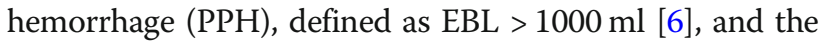
need for perioperative blood transfusion were also noted. EBL was estimated using the following formula $[4,9]$ : EBL $(\mathrm{mL})=[($ preoperative HCT - postoperative HCT $) /$ preoperative $\mathrm{HCT}] \times($ weight in kilograms $) \times 85$.

\section{Statistical analysis}

Data are expressed as mean $\pm \mathrm{SD}$, median (inter-quartile range), or $\mathrm{n}$ (\%) where appropriate. Data were assessed for normal distribution of variance using the KolmogorovSmirnov test. Normally distributed data were assessed by one-way analysis of variance. Nonnormally distributed data were assessed by the Kruskal-Wallis test. Categorical variables were assessed using the Chi-square test or Fisher exact test where appropriate. The Chi-square trend test (linear-by-linear association) was used to analyze the frequency of administration of additional uterotonic agents in the six groups. Statistical analyses were performed using SPSS version 16.0 (SPSS Inc., Chicago, IL, USA). $P<0.05$ was considered statistically significant.

The dose-response relation for oxytocin infusion was determined using probit regression [10, 11]. An effective oxytocin infusion rate (success) was defined as a rate that provided adequate UT throughout the $\mathrm{CD}$, from initiation of the oxytocin infusion to closure of the peritoneum, in the absence of administration of additional uterotonic agents. Data for successful responses for each infusion rate were used to plot a sigmoid dose-response curve. The $\mathrm{ED}_{50}$ and $\mathrm{ED}_{95}$ of an effective oxytocin infusion rate were then determined.

\section{Sample size calculation}

The sample size was estimated using the CochranArmitage Test for the trend in proportions using PASS ${ }^{\circ}$ (Version 11.0.7, NCSS, LLC, Kaysville, UT). Based on pilot data in which the proportion of parturients with adequate UT was $0.5,0.5,0.7,0.8,0.85$, and 0.9 in those receiving oxytocin infusions at a rate of $0,1,2,3,5$, or 8 $\mathrm{IU} \mathrm{h}^{-1}$, respectively, a total sample of 78 subjects (13 per group) were required to achieve $90 \%$ power to detect a liner trend using a two-sided $\mathrm{Z}$ test with continuity correction and a significance level of 0.05 . We planned to recruit150 subjects to account for potential attrition.

\section{Results}

Of a total 150 parturients who were enrolled, 145 completed the study (Fig. 1). There were no significant baseline differences among the six groups in demographic characteristics or preoperative $\mathrm{Hb}$ and $\mathrm{HCT}$ values (Table 1).

The adequacy of UT during CD in the setting of each of the 6 randomized groups is summarized in Fig. 2 . Using probit analysis, the dose-response curve was plotted (Fig. 3) from which we estimated the $\mathrm{ED}_{50}$ to be $0.05 \mathrm{IU} \mathrm{h}^{-1}$ (95\% confidence interval [CI] -2.51 to 1.25 $\mathrm{IU} \mathrm{h}^{-1}$ ) and the $\mathrm{ED}_{95}$ to be $7.72 \mathrm{IU} \mathrm{h}^{-1}$ (95\% CI 5.80 to $12.67 \mathrm{IU} \mathrm{h}^{-1}$ ).

The results of the secondary outcomes are summarized in Table 2. The proportion of study subjects who required administration of supplemental oxytocin boluses or alternative uterotonic agents decreased with increasing oxytocin infusion rates. Compared with the placebo infusion group, fewer patients in the 3,5 , and 8 $\mathrm{IU} \mathrm{h}^{-1}$ oxytocin groups needed rescue oxytocin bolus

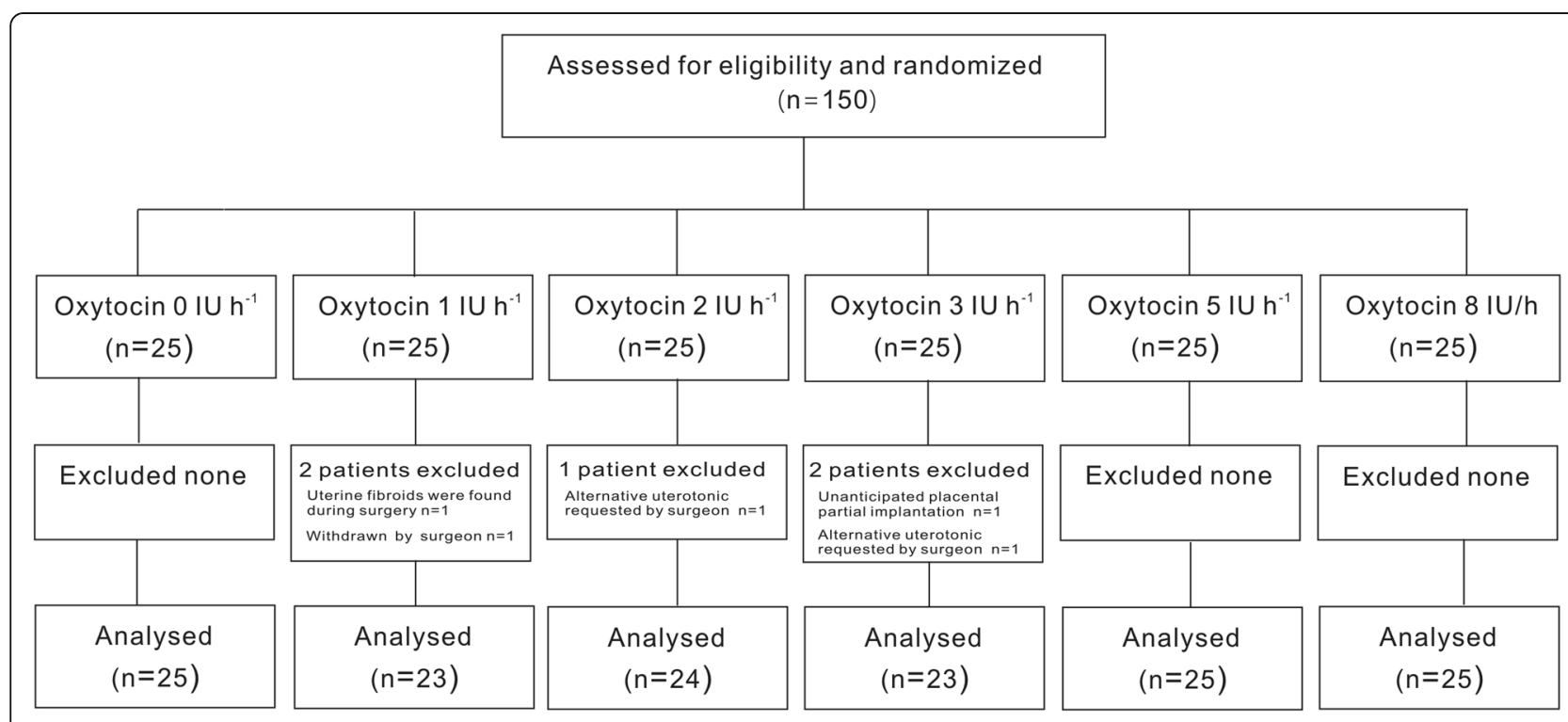

Fig. 1 Study flow diagram. IU, units 
Table 1 Demographic and obstetric data

\begin{tabular}{|c|c|c|c|c|c|c|c|}
\hline & $0 I U h^{-1}$ & $1 \mathrm{IUh} \mathrm{h}^{-1}$ & $2 I U h^{-1}$ & $3 I U h^{-1}$ & $5 \mathrm{IU} \mathrm{h} \mathrm{h}^{-1}$ & $8 I U h^{-1}$ & $P$ value \\
\hline Age (yr) & $34 \pm 5$ & $34 \pm 5$ & $32 \pm 4$ & $34 \pm 4$ & $32 \pm 4$ & $33 \pm 4$ & 0.108 \\
\hline Weight (kg) & $69.1 \pm 6.9$ & $67.5 \pm 7.1$ & $68.3 \pm 8.0$ & $67.8 \pm 7.3$ & $70.6 \pm 8.0$ & $66.5 \pm 6.7$ & 0.463 \\
\hline Height $(\mathrm{cm})$ & $160.8 \pm 3.8$ & $159.6 \pm 4.5$ & $160.3 \pm 3.9$ & $158.7 \pm 4.0$ & $160.7 \pm 5.1$ & $159.9 \pm 5.0$ & 0.590 \\
\hline Prior CD & $1(0-1)$ & $1(0-1)$ & $1(0-1)$ & $1(0-1)$ & $1(0-1)$ & $1(0-1)$ & 1.000 \\
\hline Gestational age (wk) & $38 \pm 1$ & $38 \pm 1$ & $38 \pm 2$ & $38 \pm 1$ & $38 \pm 1$ & $38 \pm 1$ & 0.989 \\
\hline Duration of surgery (min) & $38.8 \pm 8.6$ & $42.8 \pm 9.7$ & $40.5 \pm 7.8$ & $38.4 \pm 8.9$ & $39.2 \pm 8.6$ & $38.2 \pm 9.1$ & 0.479 \\
\hline Preoperative $\mathrm{Hb}\left(\mathrm{g} \mathrm{dL}^{-1}\right)$ & $12.1 \pm 0.8$ & $12.2 \pm 1.0$ & $11.7 \pm 1.3$ & $12.1 \pm 1.0$ & $11.6 \pm 1.1$ & $12.1 \pm 0.8$ & 0.172 \\
\hline Preoperative HCT (\%) & $35.9 \pm 2.3$ & $35.8 \pm 2.9$ & $35.2 \pm 3.4$ & $35.7 \pm 2.4$ & $34.5 \pm 2.5$ & $36.1 \pm 2.1$ & 0.289 \\
\hline
\end{tabular}

Data are expressed as mean $\pm \mathrm{SD}$, except prior $\mathrm{CD}$ which is expressed as median (inter-quartile range). $C D$ Cesarean delivery, $H b$ hemoglobin, $H C T$ hematocrit

( $52 \%$ vs 17,12 , and $8 \% ; P=0.012,0.002$, and 0.001 , respectively) or secondary uterotonic agents $(24 \%$ vs 0,0 , and $0 \% ; P=0.023,0.022$, and 0.022 , respectively). No significant differences in EBL and total i.v. crystalloid volume infused were observed. $\mathrm{Hb}$ and HCT levels measured at the time of PACU discharge and on postoperative day 1 were similar among the groups. There were no cases of $\mathrm{PPH}$, postoperative $\mathrm{Hb}<7 \mathrm{~g} \mathrm{dl}^{-1}$, or postoperative HCT $<24 \%$ observed. No parturients received blood transfusion perioperatively.

Side effects are shown in Table 3. We found no significant differences in the incidence of hypotension, tachycardia, nausea, flushing, and chest pain. Tachycardia was observed in one parturient who received the $8 \mathrm{IU} \mathrm{h}^{-1}$ oxytocin infusion. No parturients experienced bradycardia, vomiting, or dyspnea during the study period.

\section{Discussion}

The primary finding of this dose-response study was that, in nonlaboring women undergoing elective $\mathrm{CD}$, the $\mathrm{ED}_{50}$ of an oxytocin infusion was $0.05 \mathrm{IU} \mathrm{h}^{-1}(95 \% \mathrm{CI}-$
2.51 to $1.25 \mathrm{IU} \mathrm{h}^{-1}$ ) and the $\mathrm{ED}_{95}$ was $7.72 \mathrm{IU} \mathrm{h}^{-1}$ (95\% CI 5.80 to $12.67 \mathrm{IU} \mathrm{h}^{-1}$ ). In addition, fewer parturients in 3,5 , and $8 \mathrm{IU} \mathrm{h}^{-1}$ oxytocin infusion groups required rescue oxytocin bolus or secondary uterotonic agents compared with placebo. Finally, no significant differences in the EBL or the incidence of oxytocin-related side effects were observed among groups.

The $\mathrm{ED}_{90}$ of oxytocin as an infusion (without a preinfusion bolus) during elective $\mathrm{CD}$ has been previously estimated to be between $16.2 \mathrm{IU} \mathrm{h}^{-15}$ and $17.4 \mathrm{IU} \mathrm{h}^{-1}$ [12]. We found that when a pre-infusion bolus is administered, the $\mathrm{ED}_{95}$ of an oxytocin infusion is reduced to $7.72 \mathrm{IU} \mathrm{h}^{-1}$. The finding that the $\mathrm{ED}_{95}$ of an oxytocin infusion in the setting of a pre-infusion bolus is lower than without is clinically significant because it suggests that lower doses overall may be needed when administered in this fashion. By administering lower doses, the risk for side effects would presumably also be decreased, thus improving the care of this patient population.

The finding that the $\mathrm{ED}_{95}$ of an oxytocin infusion in the setting of a pre-infusion bolus is lower than without

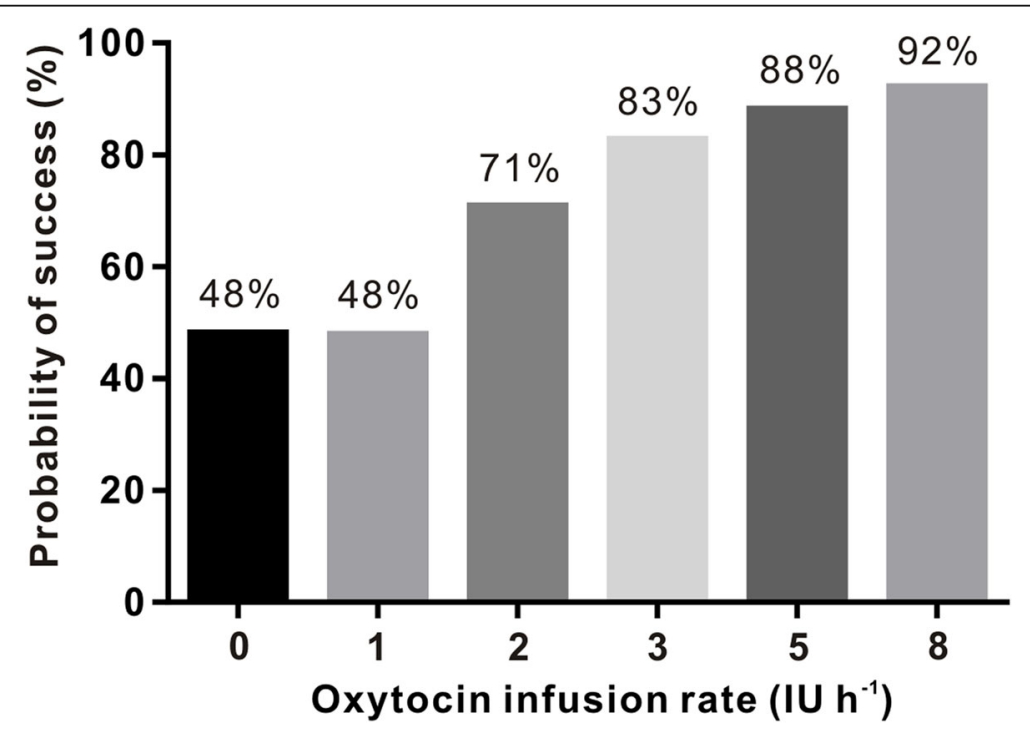

Fig. 2 The proportion of study subjects with adequate uterine tone with different infusion rates of oxytocin 


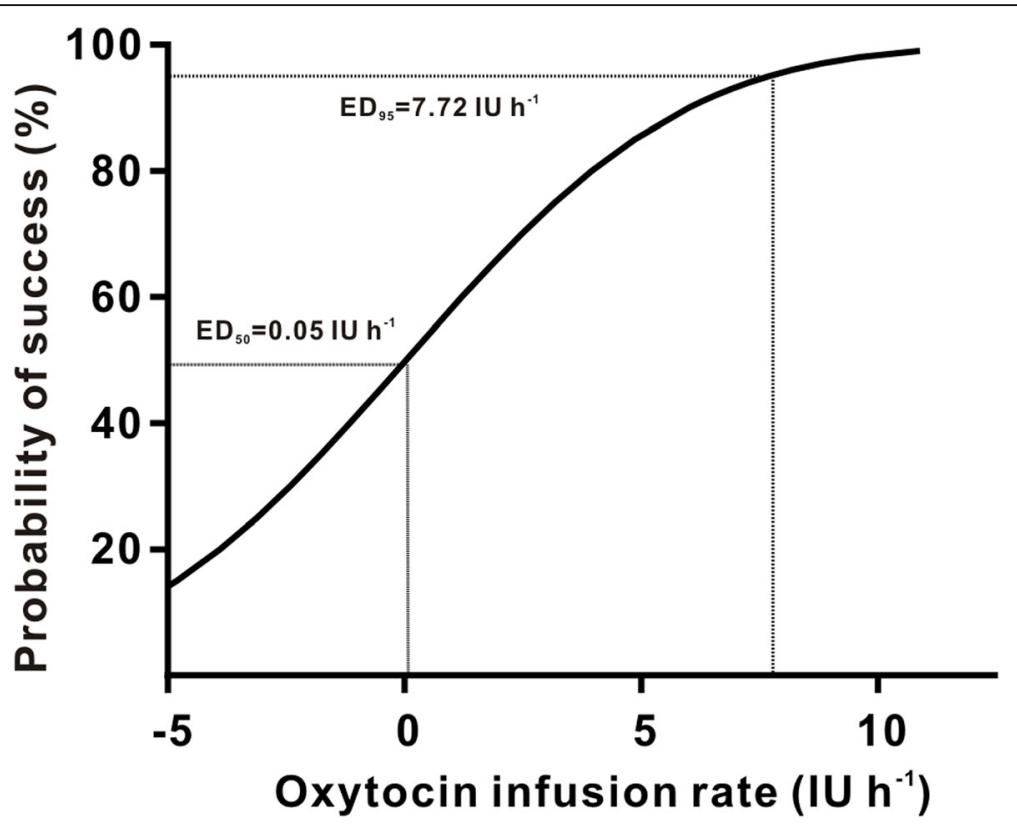

Fig. 3 The $E D_{50}$ and $E D_{95}$ of oxytocin infusion. Regression plot of the probit value vs. the infusion rate of oxytocin. The 0.5 and $0.95 \mathrm{y}$-intercepts indicate the $\mathrm{ED}_{50}$ and $E \mathrm{D}_{95}$, respectively

is not entirely surprising. The basic principles of pharmacokinetics dictate that bolus administration of oxytocin results in rapid attainment of therapeutic plasma concentrations [5]. Therefore, the purpose of the infusion in this setting is simply to maintain those levels after the initial bolus. On the other hand, when an infusion is started without a bolus, there will be a delay until therapeutic plasma concentrations are attained, which may increase the risk for uterine atony.

Our study is consistent with prior study which emphasize that a bolus of oxytocin alone is insufficient [9]. When compared to the placebo group (no oxytocin infusion), those who received an infusion of 3,5 , and 8 $\mathrm{IU}^{-1}$ required fewer rescue oxytocin boluses or secondary uterotonic agents. This finding is not surprising because oxytocin has an extremely short half-life (4-10 min) [9], so in order to maintain UT after the initial bolus, an infusion would be absolutely necessary.

While our study findings have important clinical implications, there are several limitations that should be considered. First, given that assessment of adequate UT was done subjectively, it is unknown if similar results might be obtained if a different set of obstetricians made the assessment. However, given that Lavoie et al. [5] and George et al. [12] obtained similar results using similar methods, it is likely that our results would be similar even if UT were to be assessed by different providers. Second, because we studied only nonlaboring parturients undergoing elective $\mathrm{CD}$, it is likely that the $\mathrm{ED}_{95}$ would be different if studying in a different population. Finally, while we chose to administer a bolus of 1 IU because it is well above the $\mathrm{ED}_{90}$ oxytocin [4], a smaller or larger

Table 2 Secondary outcomes

\begin{tabular}{|c|c|c|c|c|c|c|c|}
\hline & $0 I U h^{-1}$ & $1 I U h^{-1}$ & $2 I U h^{-1}$ & $3 I U h^{-1}$ & $5 I U h^{-1}$ & $8 I \mathrm{Uh}^{-1}$ & $P$ value \\
\hline Estimated blood loss (ml) & $693 \pm 426$ & $701 \pm 394$ & $619 \pm 322$ & $631 \pm 404$ & $625 \pm 472$ & $658 \pm 330$ & 0.977 \\
\hline Intravenous crystalloid (ml) & $900 \pm 210$ & $993 \pm 283$ & $992 \pm 273$ & $1004 \pm 296$ & $1024 \pm 255$ & $984 \pm 206$ & 0.622 \\
\hline $\mathrm{Hb}$ in PACU $\left(\mathrm{g} \mathrm{dL}^{-1}\right)$ & $10.7 \pm 1.0$ & $10.8 \pm 1.3$ & $10.5 \pm 0.9$ & $10.9 \pm 1.1$ & $10.8 \pm 1.2$ & $10.7 \pm 0.9$ & 0.864 \\
\hline HCT in PACU (\%) & $32.4 \pm 2.8$ & $32.2 \pm 3.8$ & $31.7 \pm 2.9$ & $32.5 \pm 3.1$ & $31.9 \pm 3.4$ & $32.1 \pm 2.5$ & 0.956 \\
\hline $\mathrm{Hb}$ on postoperative day $1\left(\mathrm{~g} \mathrm{dL}^{-1}\right)$ & $11.5 \pm 1.1$ & $11.3 \pm 1.5$ & $11.3 \pm 1.1$ & $11.8 \pm 1.3$ & $11.1 \pm 1.1$ & $11.6 \pm 1.0$ & 0.354 \\
\hline HCT on postoperative day 1 (\%) & $34.0 \pm 3.0$ & $33.3 \pm 4.3$ & $33.5 \pm 3.0$ & $34.7 \pm 3.5$ & $32.6 \pm 2.9$ & $34.2 \pm 2.7$ & 0.303 \\
\hline Rescue oxytocin required [n (\%)] & $13(52)$ & $12(52)$ & $7(29)$ & $4(17)^{a}$ & $3(12)^{b}$ & $2(8)^{c}$ & 0.000 \\
\hline Secondary uterotonic agents required $[\mathrm{n}(\%)]$ & $6(24)$ & $1(4)$ & $1(4)$ & $0(0)^{d}$ & $0(0)^{\mathrm{e}}$ & $0(0)^{f}$ & 0.000 \\
\hline
\end{tabular}

Data are expressed as mean \pm SD or $\mathrm{n}(\%)$. Compared with $0 \mathrm{IU} \mathrm{h}-1$ oxytocin infusion group, fewer patients in the 3,5 , and $8 \mathrm{IU} \mathrm{h}-1$ oxytocin groups needed rescue oxytocin bolus $\left(52 \%\right.$ vs 17,12 , and $8 \%$; ${ }^{a} P=0.012,{ }^{b} 0.002$, and ${ }^{c} 0.001$, respectively) or secondary uterotonic agents $\left(24 \%\right.$ vs 0,0 , and $0 \%$; ${ }^{\mathrm{d}} P=0.023,{ }^{\mathrm{e}} 0.022$, and ${ }^{\mathrm{f}} 0.022$, respectively). PACU postanesthetic care unit, $\mathrm{Hb}$ hemoglobin, $H C T$ hematocrit 
Table 3 Oxytocin-related adverse effects

\begin{tabular}{|c|c|c|c|c|c|c|c|}
\hline & $0 U^{-1}$ & $1 \mathrm{Uh}^{-1}$ & $2 \mathrm{Uh}^{-1}$ & $3 \cup h^{-1}$ & $5 U^{-1}$ & $8 U^{-1}$ & $P$ value \\
\hline Hypotension & $5(20)$ & $4(17)$ & $4(17)$ & $4(17)$ & $3(12)$ & $2(8)$ & 0.879 \\
\hline Tachycardia & 0 & 0 & 0 & 0 & 0 & $1(4)$ & 1.000 \\
\hline Nausea & $5(20)$ & $3(13)$ & $2(8)$ & $1(4)$ & $2(8)$ & $3(13)$ & 0.604 \\
\hline Flushing & $5(20)$ & $6(26)$ & $5(21)$ & $6(26)$ & $5(20)$ & $5(20)$ & 0.986 \\
\hline Chest pain & $4(16)$ & $2(9)$ & $1(4)$ & $1(4)$ & $1(4)$ & $2(8)$ & 0.582 \\
\hline
\end{tabular}

Data are expressed as $\mathrm{n}(\%)$

bolus could have altered the $\mathrm{ED}_{95}$. Further studies should be performed to determine if a similarly low $E D_{95}$ of oxytocin infusion is found if a lower bolus dose of oxytocin is used.

\section{Conclusions}

This study demonstrates that the $\mathrm{ED}_{95}$ of oxytocin infusion is decreased when a small bolus of oxytocin is administered prior the infusion. This finding is important because excessive oxytocin administration is associated with side effects, including nausea, vomiting, and hypotension. Future studies should be performed to better understand if a smaller dose of the bolus could be used and still result in an overall decreased need for oxytocin infusion.

\section{Abbreviations}

CD: Caesarean delivery; EBL: Estimated blood loss; ED: Effective dose; Hb: Haemoglobin; HCT: Haematocrit; HR: Heart rate; NIBP: Non-invasive blood pressure; PACU: Post anaesthetic care unit; PPH: Postpartum haemorrhage; UT: Uterine tone

\section{Acknowledgements}

We would like to thank all obstetric staffs for their help.

\section{Authors' contributions}

$\mathrm{XQ}$ helped in designing the study and writing the first draft of the manuscript; DD helped in analyzing data and writing the manuscript; CL helped in patient recruitment and data collection; FG helped in patient recruitment and data collection; LW helped in patient recruitment and data collection; XC helped in designing the study and writing the manuscript. All authors read and approved the final manuscript.

\section{Funding}

This research was supported by the Zhejiang Provincial Natural Science Foundation of China under grant NO.LY15H150007; and the National Natural Science Foundation of China under grant NO. 81471126 and NO.81501702. The funding help in the data collection, data analysis and the manuscript writing.

\section{Availability of data and materials}

All data generated or analysed during this study are included in this published article.

\section{Ethics approval and consent to participate}

The Ethical Committee of the Women's Hospital, Zhejiang University School of Medicine (Hangzhou, China) approved the study on April 5, 2018. The reference number is No. 20180010. The written informed consent from all parturients participated in the present study were obtained.

\section{Consent for publication}

Not applicable.
Competing interests

The authors declare that they have no competing interests.

\section{Author details}

${ }^{1}$ Department of Anesthesia, Women's Hospital, Zhejiang University School of Medicine, Xueshi Road 1, Hangzhou 310006, China. ${ }^{2}$ Department of Anesthesiology and Perioperative Medicine, Tufts Medical Center, Boston, MA, USA.

Received: 6 March 2019 Accepted: 19 December 2019

Published online: 31 December 2019

\section{References}

1. West R, West S, Simons R, McGlennan A. Impact of dose-finding studies on administration of oxytocin during caesarean section in the UK. Anaesthesia. 2013;68:1021-5

2. Wedisinghe L, Macleod M, Murphy DJ. Use of oxytocin to prevent haemorrhage at caesarean section-a survey of practice in the United Kingdom. Eur J Obstet Gynecol Reprod Biol. 2008;137:27-30.

3. King KJ, Douglas MJ, Unger W, Wong A, King RA. Five unit bolus oxytocin at cesarean delivery in women at risk of atony: a randomized, double-blind, controlled trial. Anesth Analg. 2010;111:1460-6.

4. Carvalho JC, Balki M, Kingdom J, Windrim R. Oxytocin requirements at elective cesarean delivery: a dose-finding study. Obstet Gynecol. 2004;104: 1005-10.

5. Lavoie A, McCarthy RJ, Wong CA. The ED90 of prophylactic oxytocin infusion after delivery of the placenta during caesarean delivery in laboring compared with nonlaboring women: an up-down sequential allocation dose-response study. Anesth Analg. 2015;121:159-64.

6. Duffield A, McKenzie C, Carvalho B, Ramachandran B, Yin V, El-Sayed YY, Riley ET, Butwick AJ. Effect of a high-rate versus a low-rate oxytocin infusion for maintaining uterine contractility during elective cesarean delivery: a prospective randomized clinical trial. Anesth Analg. 2017;124:857-62.

7. Butwick AJ, Coleman L, Cohen SE, Riley ET, Carvalho B. Minimum effective bolus dose of oxytocin during elective caesarean delivery. Br J Anaesth. 2010;104:338-43.

8. Sartain JB, Barry JJ, Howat PW, McCormack DI, Bryant M. Intravenous oxytocin bolus of 2 units is superior to 5 units during elective caesarean section. Br J Anaesth. 2008;101:822-6.

9. Sheehan SR, Montgomery AA, Carey M, et al. ECSSIT Study Group. Oxytocin bolus versus oxytocin bolus and infusion for control of blood loss at elective caesarean section: double blind, placebo controlled, randomised trial. BMJ. 2011;343:d4661.

10. Carvalho B, Durbin M, Drover DR, Cohen SE, Ginosar Y, Riley ET. The ED50 and ED95 of intrathecal isobaric bupivacaine with opioids for cesarean delivery. Anesthesiology. 2005;103:606-12.

11. Khaw KS, Ngan Kee WD, Wong EL, Liu JY, Chung R. Spinal ropivacaine for cesarean section: a dose-finding study. Anesthesiology. 2001;95:1346-50.

12. George RB, McKeen D, Chaplin AC, McLeod L. Up-down determination of the ED (90) of oxytocin infusions for the prevention of postpartum uterine atony in parturients undergoing cesarean delivery. Can J Anesth. 2010;57: 578-82.

\section{Publisher's Note}

Springer Nature remains neutral with regard to jurisdictional claims in published maps and institutional affiliations. 